\title{
AGILE \\ FRAMEWORK BASED IOT APPLICATION FOR FIRE DETECTION
}

\author{
Dhatri Raval $^{1}$, Dr. Jaimin Undavia ${ }^{2}$ and Dr. Atul Patel ${ }^{3}$ \\ ${ }^{1,2,3}$ Faculty of Computer Science and Application, Charotar University of Science and Technology, Changa, \\ GUJARAT, INDIA \\ 1'dhatriraval.mca@charusat.ac.in, ${ }^{2}$ jaiminundavia.mca@charusat.ac.in, ${ }^{3}$ atulpatel.mca@charusat.ac.in
}

\begin{abstract}
The recent times the entire world is moving towards the automation and sensor based systems, applications and solutions. Tons of data are now generated without a single human intervention as the data collection is automated through such intelligent systems. Once you have huge amount of error free data with you, one can use it in various aspects for the betterment of any new system or system already on floor. The advent of IoT has changed the world of manufacturing industries too through installation of different sensors with high proximity. Such automated and intelligent systems are used to automate the routine process, signaling any accident, switch off/on any device which may lead to a hazard, automatic supervision of any process, etc. This article offers a framework to prevent fire accidents within the industry involving fire problems. The proposed system is going to be an IoT based solution with well equipped sensors and other triggering devices.
\end{abstract}

\section{Keywords: IoT, Sensors, Fire}

\section{Introduction}

The Internet of Things is a thrust area in the industry and research due to the vast usage of the number of smart mobile phones, sensors and the potential applications which are produced huge data from a variety of domains. Such huge amount of data is proved to be golden dust for its future perspective. The last eight years' statistics according to NCTA, number of devices are increasing five times so as the growth of the data is explosive. Figure 1 shows the ratio of the connected devices in the last eight years which indicates the high level of growth in number of connected devices every year. As per McKinsey the growth of the cloud service and IoT device will thrive in the next five years [1].

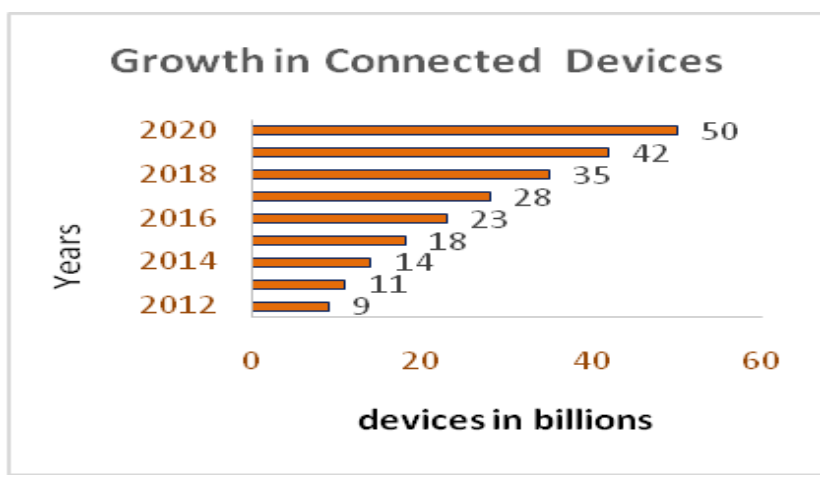

Figure 1. Growth in Connected Devices

Due to the use of the huge number of applications in connected devices, it produces a large number of Data in a heterogeneous format every second as per Gartner's review for efficient growth of business industries and companies should use data analytics [2]. Data Analytics is the key for desire growth of business. As per hype cycle, data analytics and IoT is the thrust area for the upcoming time which offers wide range of the research [3].

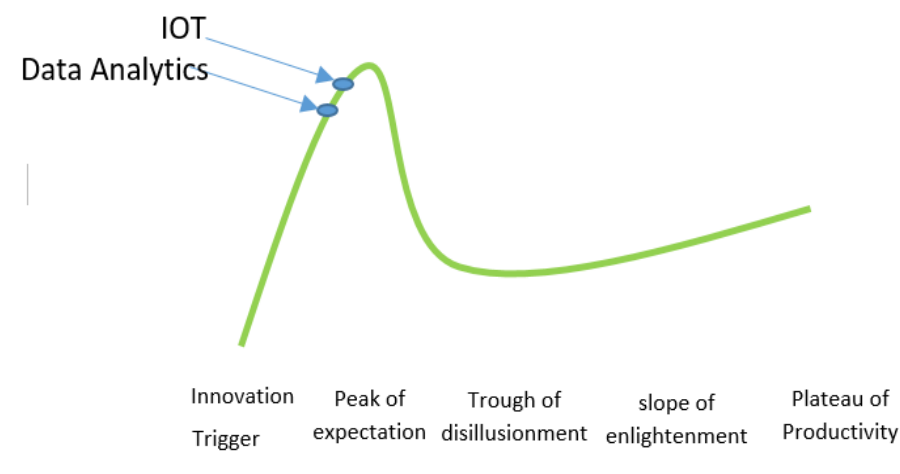

Figure 2. Hype Cycle 
IoT devices will generate 79.4 zettabytes in 2025 , It is 5.8 times more in comparison of 2019 [4]. Most IoT devices are nothing but a collection of sensor-fitted devices which are capable to capture the data without any interrupt over a long period of time [5].Such information impacting from queries of Web search to a stream of information caught by sensors are what adds to Enormous Information. Henceforth, IoT information to unveil patterns, inductions, and significant bits of knowledge is vital for administering tip to top administrations [6]. The emerging interest within the web of Things (IoT) and its by-product big knowledge want stakeholders to obviously perceive their definition, building blocks, potentials and challenges. IoT and massive amount of data have different 2 methods of relationships. In this context, IoT is responsible to produce huge amount of data and these data is the ultimate input for data analytics which is responsible to boost the processes and services of IoT [7]. IOT generate massive data which are categorized in four types [8]

1) Heterogeneous: data may be in form of structures and semi-structures way. For example, object of any gis, biological unit of data, etc.

2) Massive: A huge number of devices connected to the net will establish not solely billions however trillions of time knowledge. Such data desires an outsized storing area and a robust system to process. Imagine a situation in a very place of business wherever innumerable merchandizes is on the market daily. If these objects ought to be tracked per day, and every trailing generates one hundred bytes' data.

3) Rich semantic: The implication drawn is that the ability among the "things" is one in every of the utter elementary necessities for object addressing, tracking, and discovery.

4) Timeliness: Historical knowledge is important however, the timely data will describe the standing of an object in the period during an additional precise purpose of view.

\section{Literature review: IOT applications with Data Analytics}

[9]Smart cities: The writer spoke about IoTdata analysis collaboration. Issues related to big data.Collect data from several outlets, such as smart phones, social media, data from different sectors, and people from smart cities.

[10]smart homes: For smart Energy control on the IoT and Big Data systems. The article shows the device architecture uses data analytics and elastic storage. Building a smart EMS to support various stakeholders with their needs their respective rights. The framework allows users to do so remotely. Monitor and control devices, and the generation of online bills via a convenient mobile application user interface.

[11]Big data analytics using IoT: the author describes how to pre-process the raw data which are generated by connected devices and discussed various platforms of big data analysis.

[12]This paper introduced the Smart Home IOT Big Data Analytics platform with fog and cloud computing. A thorough review of the requirement and the components of the platform. The method of performing analytics in the fog node is presented, and the results indicate the potential implementations of the device in various aspects. The systems acquired data can include the identification of behaviors to recognize health issues, identify trends of energy use and energy saving planning, and forecast the maintenance schedule of appliances to prevent costly repairs.

[13]The proposed smart model in the paper: A smart model for agriculture is intended to predict the yield of the crop and settle on a better crop sequence. Based on the previous crop sequence, in the same farmland with current information on soil nutrients. By use of real-time sampling soil, the farmer will be able to meet the existing requirements for fertilizer the grain of agriculture. As data were collected crop information and soil conditions are given in this model by Big-Data review of the best crop series, next crop to be cultivated improved production, total production of crops in the region of interest, complete requirements for 
fertilizers, and other data of interest may be given analyzed. The model also facilitates the calculation of the total output and wise total fertilizer per crop area requirements for this.

[14]In this article, the writer developed a system: The automotive parking smoke alert observation system is Using Arduino. The method described can track and trace the hearth smoke within the park by a process the smoke sensitivity worth that area unit is taken by the MQ-2 gas smoke detector. Then, this archetype system can inform the user.

N. Savita, et al, shows fireplace safetyconnected work done and analysis of various techniques accustomed to finding the fire. According to the writers' analysis, more than $50 \%$ of systems used sensors, $27 \%$ of the system based on image processing, and the rest are based on video processing[15].

[16]The author has given the situation of firefighting application in china. They mentioned regarding IoT device within the supervising of fighting product quality, observance of construction firefighting facilities, maintenance of firefighting facilities, home firefighting safety, firefighting instrumentality. Additionally, mention the analysis, benefits, and suggestions for burning IoT [17].

The paper is basically targeting the economical advancements through various projects of Big Data Analytics. The primary purpose of the study is to move smartly and effective management of various events. The great analysis and discussion are disbursed concerning the energy harvest using electricity for health observance sensors. The data analytics is performed using the Hadoop server with MapReduce mechanism. A range of datasets is examined, evaluated, analyzed and tested, supported that is shown that however health care is performed using data analytics

\section{IoT and Data Analytics application domains}

Application areas categorized from the survey are mainly categorized into three themes society, environment, and economy. Figure 3 shows the domains using IoT, and Data Analytics. The categorize

$\mathrm{d}$ are interconnected. Some are interconnections are shown in the figure.

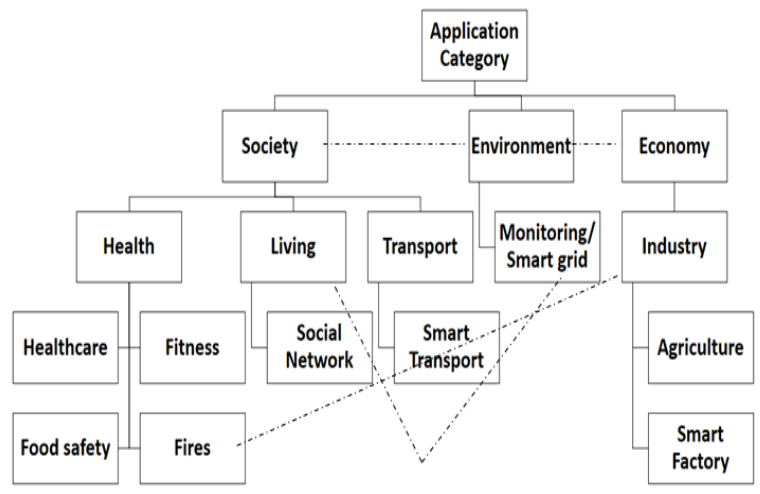

Figure 3. Applications Domain

\section{Table 1. Survey relevant to domains}

\begin{tabular}{|l|l|}
\hline Theme & Reference \\
\hline Society & {$[10][12][14][9][7][15]$} \\
\hline Environment & {$[15][16]$} \\
\hline Economy & {$[18][14][16][13]$} \\
\hline
\end{tabular}

\section{Proposed System}

Using Agile, the proposed framework was planned model for development. Iterative and spiral model are also there but Agile is better. The goal is to achieve agility by eliminating repetitive activities that consume time and effort. The model of agile development is one of the methodologies that emphasize a constant requirement Collection to create a scheme or substance that is built essentially from the initial prototype and a prototype clarification efficient. Such technique enables the creator moves from one stage to another and goes from one stage to another. Back to the preceding point. For this there are six stages: Methodology: (i) based on the requirement gathering plan the system; (ii) design the systems blue print based on available data gathering; (iii) develop the system as per blueprint; (iv) test the system; (v) release the system; (vi) take the feedback from user; Figure 4 will show the Agile phases to work. 


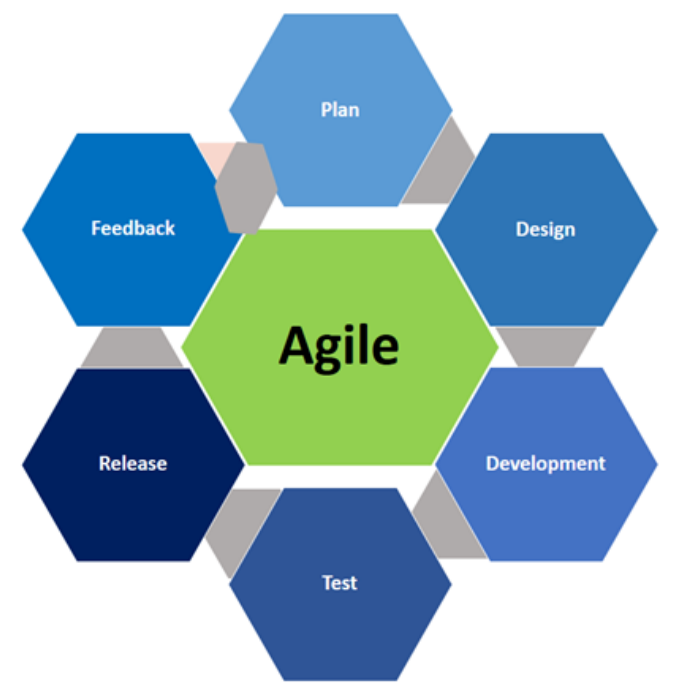

Figure 4. Agile Framework

First, all elementary system requirements are compiled and evaluated as a continuous phase to be carried out. This process initiates with the organization of all the structural and nonstructural specifications of the device. Both of them Here, the user requirements are gathered through reconciliation of user and study of same related application which is available in market. After the gathering of requirement, they are categorized according to the submission. Functionality of the program and target customers are also considered.

\subsection{Architecture of Proposed System}

Some highly flammable gases are identified which are referred as Fuel Gasses such as propylene, propane, hydrogen, acetylene, methane, etc, [19]. Such gases are start burning when they are mixed with an oxidant and subject to any ignition source [19]. It is specially used to check the amount of hydrogen in the enviourment in this proposed device used sensor MQ8. One may incorporate other sensors in the same way as the MQ8 sensor. The simulation of a functional device is seen in Figure 5. The system will calculate the amount of hydrogen If the level of hydrogen is surpass the maximum system will notify the user by buzzer and led monitor, along with data will retain on cloud using the wireless unit. The data stored by the cloud will be used for the purpose of analysis in the future.

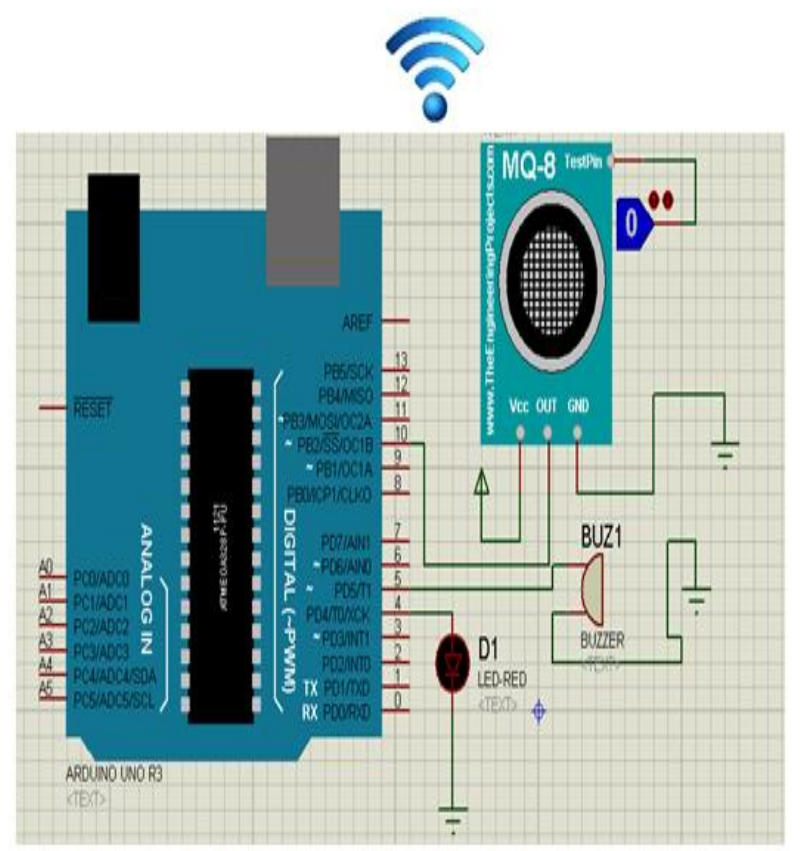

Figure 5. Proposed System Architecture

Table 2. Hardware Specification

\begin{tabular}{|l|l|}
\hline \multicolumn{1}{|c|}{ Device } & \multicolumn{1}{c|}{ Purpose } \\
\hline $\begin{array}{l}\text { Arduino Uno } \\
\text { board }\end{array}$ & As a microcontroller \\
\hline MQ8 sensor & $\begin{array}{l}\text { Check the level of hydrogen } \\
\text { in environment }\end{array}$ \\
\hline Led & $\begin{array}{l}\text { To indicate the danger level } \\
\text { of hydrogen }\end{array}$ \\
\hline Buzzer & Warn the people \\
\hline Wi-fi module & Data transfer to cloud \\
\hline Jumper wire & $\begin{array}{l}\text { Connect the sensors and } \\
\text { other equipment with } \\
\text { microcontroller. }\end{array}$ \\
\hline Usb cable & $\begin{array}{l}\text { Transfer the logic from } \\
\text { computer to microcontroller }\end{array}$ \\
\hline
\end{tabular}

\section{Conclusion}

IoT based applications playing its vital role in Medical, Military, Agriculture, Industry, Academic and in many others fields. In this paper, architecture proposed for IoT applications which can be used for fire detection. There are many sources which can cause fire. In the proposed system, data analytics algorithm can be used to detect the changes of fire. 


\section{References}

[1] Mckinsey, "https://www.mckinsey.com/business-functions/mckinsey-digital/our-insights/disruptivetechnologies\#".

[2] A. White, "https://emtemp.gcom.cloud/ngw/globalassets/en/doc/documents/465952-data-and-analyticsleaders-rewire-your-culture-for-an-ai-augmented-future.pdf," 27 Feb 2020. [Online].

[3] "https://www.gartner.com/smarterwithgartner/5-trends-drive-the-gartner-hype-cycle-for-customer-serviceand-support-technologies-2020/," [Online].

[4] "https://iotbusinessnews.com/2020/07/29/20898-iot-growth-demands-rethink-of-long-term-storagestrategies-says-idc/," [Online].

[5] Ejaz Ahmed, Ibrar Yaqoob, Ibrahim Abaker Targio Hashem, Imran Khan, Abdelmuttlib Ibrahim Abdalla Ahmed, Muhammad Imran and Athanasios V Vasilakos, "The role of big data analytics in Internet of Things," Computer Networks, 2017.

[6] E. SIOW, T. T. and W. H. , "Survey, Analytics for the Internet of Things: A Survey," ACM Computing Surveys,, pp. 74-1:74-36, 2018.

[7] Mehdi Mohammadi and Ala Al-Fuqaha, "Enabling Cognitive Smart Cities Using Big Data," IEEE, vol. 9, 2019.

[8] Suwimon Vongsingthong and Sucha Smanchat, "A Review of Data Management in Internet of Things," AsiaPacific Journal of Science and Technology, vol. 20, no. 2, 2015.

[9] Martin Strohbach, Holger Ziekow, Vangelis Gazis and and Navot Akiva, "Towards a Big Data Analytics Framework for loT and Smart City Applications," in Modeling and Optimization in Science and Technologies, AGT InternationalDarmstadtGermany, 2015, pp. 257-282.

[10] A.R. Al-Ali, Imran A. Zualkernan, Mohammed Rashid, Ragini Gupta and Mazin Alikarar, "Approach, A Smart Home Energy Management System Using IoT and Big Data Analytics," IEEE, vol. 63, no. 4, pp. 426-434, 2017.

[11] Preeti Gulia and A. Chahal, "BIG DATA ANALYTICS FOR IOT," International Journal of Advanced Research in Engineering and Technology, vol. 11, no. 6, pp. 593-603, 2020.

[12] Abdulsalam Yassine, Shailendra Singh, M. Shamim Hossain and Ghulam Muhammad, "loT Big Data Analytics for Smart Homes with Fog and cloud computing," Future Generation Computer Systems , 2018.

[13] S Rajeswari, K Suthendran and K Rajakumar, "A Smart Agricultural Model by Integrating loT, Mobile and Cloudbased Big Data Analytics," International Journal of Pure and Applied Mathematics, vol. 118, pp. 365-370, 2018.

[14] A. Anis Farihan Mat Raffei, N. Nur Syafiqah Awang, Nur Shamsiah Abdul Rahman and N. Nor Saradatul Akmar Zulkifli, "Internet of Things (IoT) Based Fire Alert Monitoring System for Car Parking," in 7th International Conference on Electrical and Electronics Engineering, 2020.

[15] N Savitha and D. S. Malathi, "A Survey on Fire Safety Measures for Industry Safety Using IOT," in The International Conference on Communication and Electronics Systems, 2018.

[16] ZHANG Ying-conga and Y. J. , "A Study on the Fire IOT Development Strategy," Procedia Engineering, vol. 52, pp. 
314-319, 2013.

[17] Min Chen, Shiwen Mao and Yunhao Liu, "Big Data: A Survey," Mobile Network and Application, vol. 19, pp. 171209, 2014.

[18] Dhananjay Singh, G. Gaurav Tripathi and Antonio J. Jara, "A survey of Internet-of-Things: Future Vision,Architecture, Challenges and Services," IEEE World Forum on Internet of Things, pp. 287-292, 2014.

[19] U. i. f. risk, "https://www.boconline.co.uk/en/health-and-safety/gas-safety/gas-risks/flammable-gasesrisks/index.html".

[20] TAUSIFA JAN SALEEM and MOHAMMAD AHSAN CHISHTI, "DATA ANALYTICS IN THE INTERNET OF THINGS: A SURVEY," Scalable Computing: Practice and Experience, vol. 20, pp. 607-629, 2019. 